Research Article

\title{
Determination of the Installation Time of Secondary Liner during Excavation of Large Cross-Section Double-Arch Tunnels
}

\author{
Jie Cai (1) \\ Transportation Infrastructure Construction Quality and Safety Supervision Bureau of Fujian Province, \\ Fuzhou, Fujian 350001, China \\ Correspondence should be addressed to Jie Cai; 1141577673@qq.com
}

Received 31 May 2020; Revised 6 August 2020; Accepted 5 December 2020; Published 18 December 2020

Academic Editor: Peixin Shi

Copyright (c) 2020 Jie Cai. This is an open access article distributed under the Creative Commons Attribution License, which permits unrestricted use, distribution, and reproduction in any medium, provided the original work is properly cited.

Double-arch tunnel construction involves in high risk due to its large span and special structural shape. In order to explore the proper installation time for the secondary liner during the excavation of large cross-sectional double-arch tunnels supported by three layers of the liner, this paper optimizes the distribution of the stress release ratio based on the analysis of surrounding rock deformation and structural stress. Proper installation time for the secondary liner is determined according to the optimization results and regressive analysis of monitoring data of initial support crown settlement. The results show that the reasonable distribution of stress release ratio is $30 \%$ during tunnel excavation, $30 \%$ after initial support installation, and $40 \%$ after secondary liner installation. After installing the initial support, the total crown settlement at three monitored sections is $51.5,52.0$, and $49.8 \mathrm{~mm}$, respectively. When the initial support crown settlement reaches $65-75 \%$ of the final value, the secondary liner should be installed, and the crown settlement is 14.4-19.5 mm, 15.3-20.5 mm, and 14.4-19.4 mm, respectively, at three monitored sections. Findings from this paper can provide reference for design and construction of similar projects.

\section{Introduction}

Double-arch tunnels are composed of two side-by-side parallel tunnels with their adjacent liners supporting on a central pillar to form an " $M$ " shape. The double-arch tunnels require smaller construction space, and thus, its alignment selection is more flexible compared with two separate parallel tunnels. It is more economical and environmentalfriendly under certain circumstances such as in densely populated urban areas or in steep mountain ridges where the construction space is limited.

New Austrian Tunnelling Method (NATM) is widely used for tunnel excavation at present. It considers that surrounding rock is the primary bearing structure in the tunnel structure system, and in order to make full use of surrounding rock self-stability, the secondary liner should be installed when the surrounding rock or initial support is basically stable after the early deformation. During tunnel excavation, part of the earth load will be released as the deformation energy, and the remaining will be undertaken by supporting structures, i.e., tunnel liners. The portion of load depends on the installation time of the tunnel liner. If applied too early, the secondary liner tends to have cracks due to excessive force, which affects the durability of the structure and even lead to damage. If the secondary liner is applied too late, the initial support may have large deformation, resulting in instability of the surrounding rock. Therefore, it is important to accurately determine the reasonable installation time for the secondary liner to ensure the structural safety and control the deformation of the surrounding rock.

Deep research has been conducted on the timing for the installation of the secondary liner [1-11]. Panet first proposed the convergence restriction method and expounded the optimal installation time for liners by introducing the concept of characteristic line of surrounding rocks and tunnel liners [3]. Sulem et al. modified the empirical formula by Panet and proposed a 
general method that can accurately judge the tunnel convergence in elastic-plastic media and analysed the time-space effect of circular tunnel and the reasonable installation time for the secondary liner $[2,4]$. Based on the convergence-constraint calculation method, Pan and Dong proposed a creep model which involved multiple factors, integrating the predicted value of convergence calculated and monitored value, so that the reasonable supporting time for the secondary liner can be determined [5]. Liu et al. judged the deformation of the surrounding rock by calculating the ratio of the daily deformation and total deformation to the simulated limit displacement, respectively, and took the limit value of the deformation ratio and the deformation rate as the basis for the timing of the secondary liner [6]. Choi and Shin et al. analysed the optimal lining time of tunnel buried in the soft rock through numerical simulation, in situ inspection, and other means based on the NATM principle [7]. Considering the rheological properties of rock mass, Zhou et al. proposed a theoretical and numerical calculation method to determine the reasonable installation time for the tunnel secondary liner and verified the reliability of the theoretical method based on field monitoring data [8]. At present, researches on timing for the installation of the secondary liner are mostly focused on the conventional tunnel with two layers of liners, while the studies of double-arch tunnels with three layers of liners are seldom reported, and thus, the proper installation time for secondary liner is still unclear. With larger underground space and more complex utilization modes, the advantages of double-arch tunnels have become increasingly obvious. With the improvement of construction technology, large-span double-arch tunnels will have more widespread application in near future. Therefore, it is urgent and necessary to study the timing for the installation of the secondary liner during the excavation of double-arch tunnels.

This paper analyses the proper installation time for the secondary liner of the Haicang double-arch tunnels in the Xiamen western passage project. The tunnel has a total excavation cross-sectional area of $498.8 \mathrm{~m}^{2}$ and minimum burial depth of $5.6 \mathrm{~m}$ in weathered rock mass and mixed ground and passes beneath main streets. It is critical to control the ground settlement due to the sensitive environment. After the completion of initial support, the secondary liner is installed in time to avoid excessive ground deformation. Compared with the conventional tunnels, the secondary liner of the double-arch tunnels bears larger loads. In order to ensure the structural safety and surrounding rock stability, the tunnels are supported by three layers of liners. Through numerical simulation, this paper investigates the stress release ratio in each construction stage considering the structural stress and surrounding rock deformation. Based on optimal distribution of stress release ratio, proper installation time for the secondary liner is determined through regressive analysis of monitoring data of the initial support crown settlement. The research results can provide reference for the design and construction of similar projects worldwide.

\section{Project Backgrounds}

The Haicang double-arch tunnels are the critical component of the Xiamen second western passage project. The project is a three-lane in each direction roadway tunnel connecting the Haicang district and Xiamen island in Fujian province, southeast of China. The project has a design speed of $80 \mathrm{~km} /$ $\mathrm{h}$, design life of 100 years, total alignment length of $7.1 \mathrm{~km}$, and construction budget of 8.1 billion USD. The excavation started in April 2016 and is expected to complete in December 2019.

Figure 1 shows a plane view of the project which starts at Haicang Avenue in Haicang District through open-cut, passes beneath the Xiamen West Sea, and enters the Xiamen island at Xiangyu Port through conventional tunnelling and ends at Shigushan Interchange in Xiamen island through open-cut. The project was divided into contracts: A1, A2, and A3. The Haicang double-arch tunnels belong to contract A2. It has a total alignment length of $160 \mathrm{~m}$ connected with the $1890-\mathrm{m}$ horseshoe tunnel section in the west and the 140-m open-cut tunnel section in the east.

Figures 2 and 3 show the plan and cross-sectional view of the double-arch tunnels, respectively. Figure 3 shows that the span of the double-arch tunnels varies from $40.01 \mathrm{~m}$ to $45.73 \mathrm{~m}$ and the height varies from $13.25 \mathrm{~m}$ to $15.06 \mathrm{~m}$. The maximum excavation cross-sectional area of two tunnels is $498.8 \mathrm{~m}^{2}$. Figure 2 shows that the surrounding construction environment is sensitive. Buildings and utilities are so densely distributed nearby the construction site that the minimum distance between buildings and the excavation boundary is only $4.3 \mathrm{~m}$, which limits the construction space. There are also various underground utilities around the tunnel, and the minimum distance between the pipelines and the excavation boundary is only $3.2 \mathrm{~m}$. It is critical to control the ground deformation and protect the adjacent buildings and utilities during tunnelling.

Figure 4 shows the local ground conditions along the alignment. In general, the subsurface strata consist of 5 to $13 \mathrm{~m}$ of soils underlain with bedrock with different degree of weathering. The bedrock is granite with occasional diabase intrusions. The top of the rock along the tunnel alignment varies significantly. The double-arch tunnels are mostly buried in completely weathered to moderately weathered rock mass, except at the east end of the alignment where the tunnel is buried in mixed ground. Within the mixed ground, the upper part of the tunnel face is buried in residual soils classified as gravelly clay (stratum 2) and completely weathered rock mass (stratum 5-1), and the lower part of the tunnel face is buried in heavily weathered rock mass (stratum 5-2). The local groundwater table is about $2 \mathrm{~m}$ below the ground surface and is connected with the West Xiamen Sea. The fill material (stratum 1), residual soil (stratum 3), completely weathered rock mass (stratum 5-1), and heavily weathered rock mass (stratum 5-2) have a high permeability ranging from $10-4$ to $10-2 \mathrm{~cm} / \mathrm{sec}$, and thus, it is important to control the groundwater intrusion during excavation. 


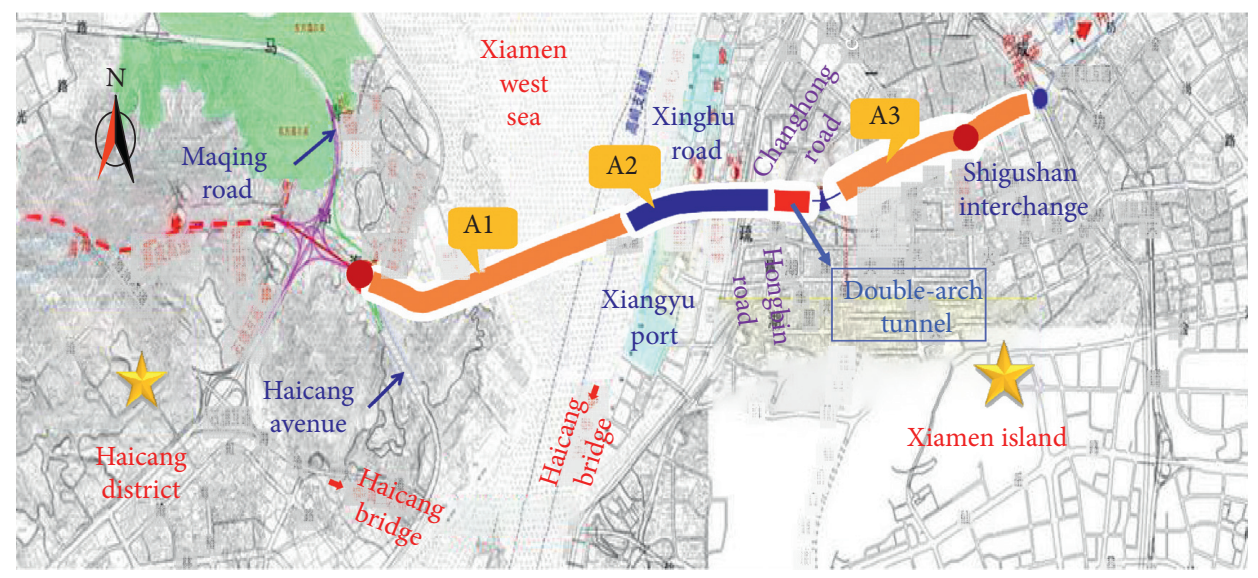

Figure 1: Plan view of the Second Western Passage project.

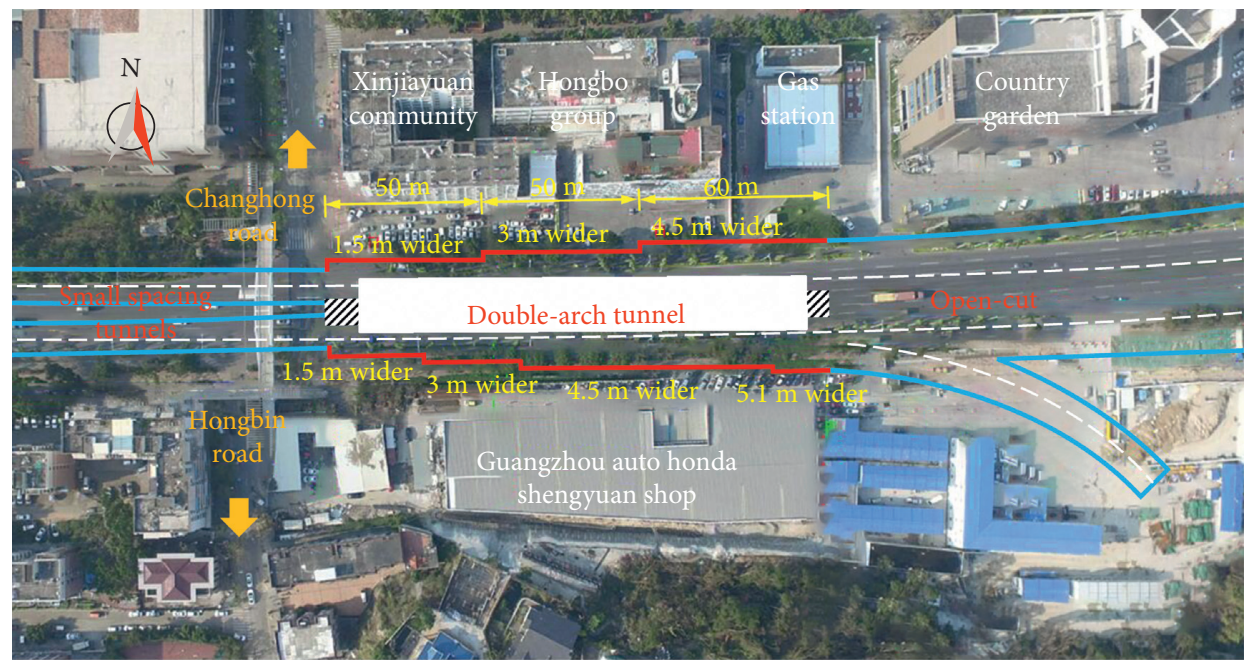

FIgURE 2: Plan view of double-arch tunnels.

Due to the large excavation cross section, poor ground conditions, and sensitive surrounding environment, it requires engineering means and methods to protect the excavation stability and control the ground deformation during construction.

\section{Numerical Analysis of the Timing of Liners}

In order to better simulate the process of stress release, stress release ratio is changed in different simulation stages to better reflect time and space effects. For example, finite element software Midas/GTS can be used to set different load release coefficient under any excavation stage to reflect the stress release ratio of the surrounding rock. The state of the surrounding rock before and after tunnel excavation is shown in Figure 5. $\sigma_{\mathrm{A}}$ represents the inner stress of part $\mathrm{A}$ before excavation and $\sigma_{\mathrm{B}}$ is the surrounding rock stress. To keep balance between part $A$ and $B$ before excavation, suppose $F_{\mathrm{AB}}$ as balanced load on $\mathrm{B}$ posed by $\mathrm{A}$ and $F_{\mathrm{BA}}$ as balanced load on A posed by B. The balanced load is related to inner stress and self-gravity of part $\mathrm{A}$, which can be expressed as below:

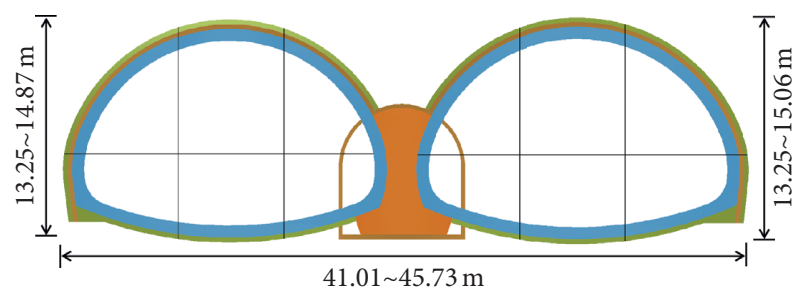

Figure 3: Cross section of the double-arch tunnels.

$$
F_{\mathrm{BA}}=-F_{\mathrm{AB}}=-\int_{V_{\mathrm{A}}} B^{T} \sigma_{A} d V_{A}+\int_{V_{A}} N^{T} \gamma d V_{A},
$$

where $\mathrm{B}$ is the strain-displacement relation matrix; $V_{\mathrm{A}}$ is the excavation volume; $\mathrm{N}$ is the unit function; and $\gamma$ is the bulk density of surrounding rock. After part A was excavated, $F_{\mathrm{AB}}$ disappeared and Midas/GTS will automatically calculate according to the balanced load and pose reverse load on excavation contour in certain proportion. If load release coefficient is set as $40 \%$, then the proportion is $60 \%$, i.e., $60 \%$ of balanced load is posed on excavation boundary. The load $\mathrm{F}$ can be expressed as follows: 

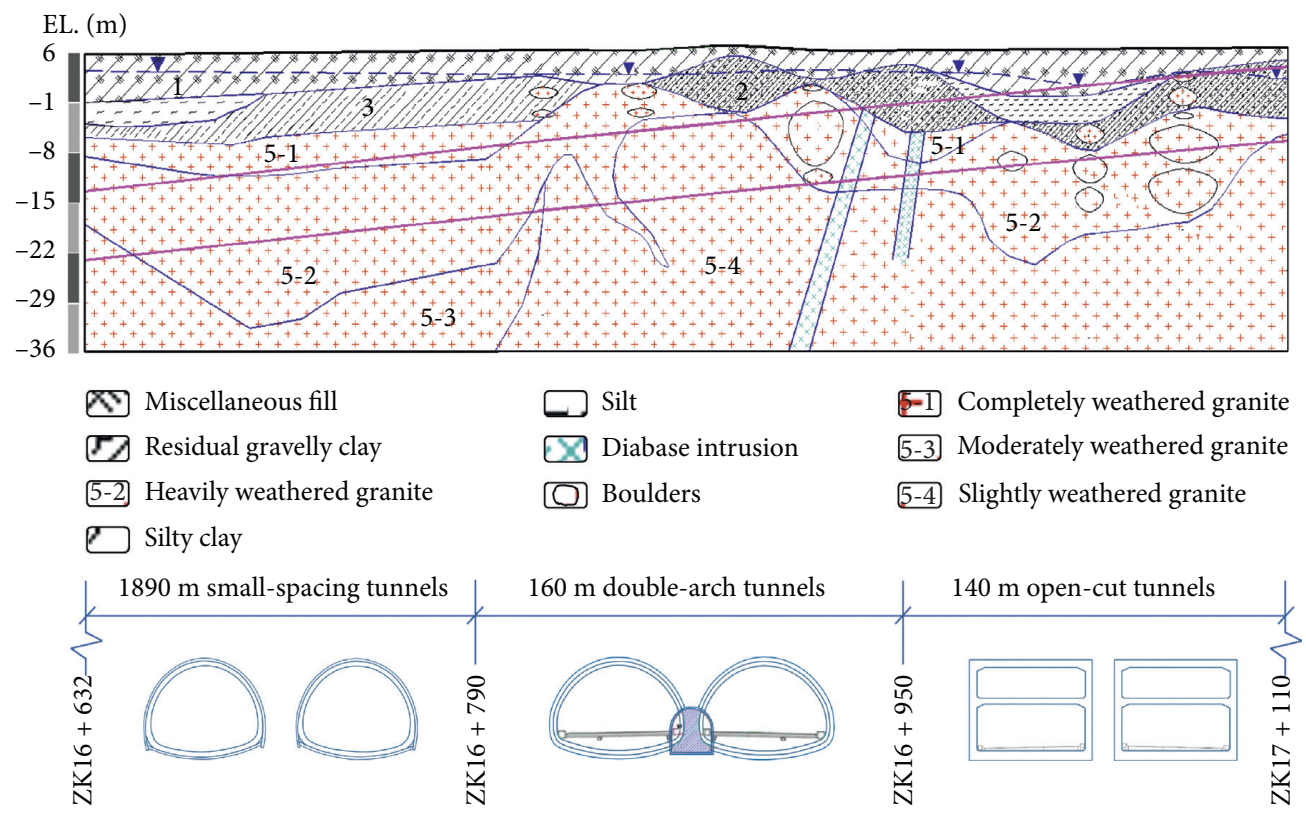

FIgURE 4: Geotechnical profile and typical cross sections.

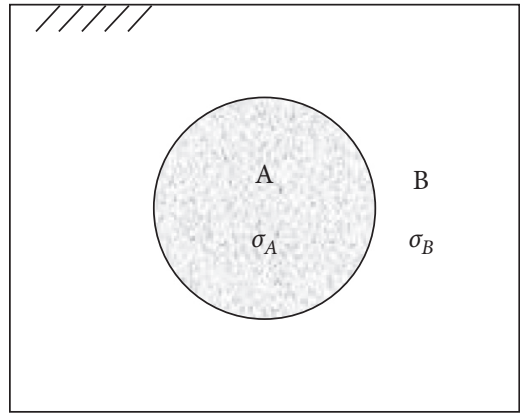

(a)

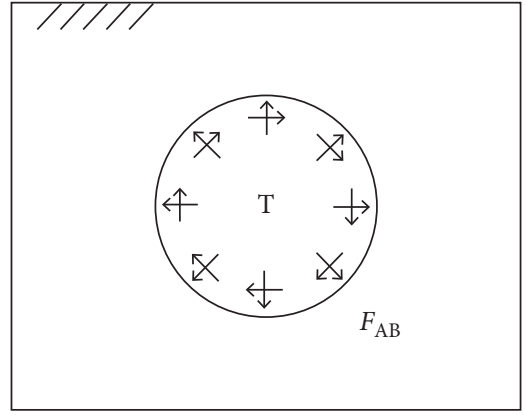

(b)

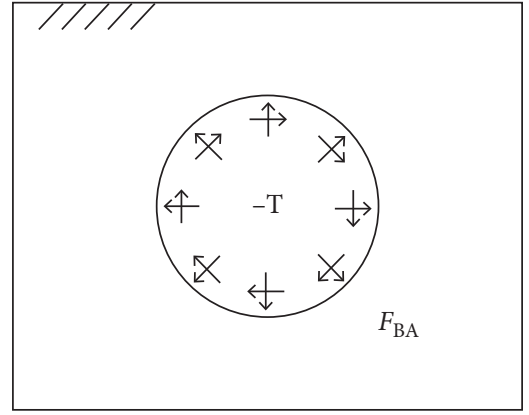

(c)

Figure 5: State of the surrounding rock before and after excavation. (a) Before excavation. (b) Load on B posed by A after excavation. (c) Load on A posed by B after excavation.

$$
F=60 \% \times F_{\mathrm{BA}}=\left(-\int_{V_{A}} B^{T} \sigma_{A} d V_{A}+\int_{V_{A}} N^{T} \gamma d V_{A}\right) \times 60 \%
$$

Above all, the outer balanced load and inner self-stability of the surrounding rock are combined together to maintain stability after tunnel excavation. In fact, the released stress is balanced load. Stress of the surrounding rock can be completely released after certain excavation stage, i.e., the total of stress release ratio in each excavation stage should be less than $100 \%$.

\section{Analysis of Stress Release Ratio of Surrounding Rock}

In order to explore proper time for liners, stress release ratio is changed under different simulation stages and stability, and safety of the surrounding rock is compared to ascertain proper distribution of stress release ratio.
4.1. FE Model. A finite element software Midas/GTS was used to simulate the excavation process and investigate the stress in the tunnel liners and central pillar as well as the ground deformation. A two-dimensional model was constructed. The simulation cross section was chosen at Sta. ZK16 + 950 where the ground is mixed strata consisting of residual soil on the top, completely weathered rock mass in the middle, and moderately weathered rock mass at the bottom. Figure 6 shows the FE model of the tunnel. The model has a dimension of $200 \mathrm{~m}$ by $60 \mathrm{~m}$. After meshing, the model consists of 13452 nodes and 3498 elements.

The soil strata were assumed as the Mohr-Coulomb material with the parameters listed in Table 1 . The doublearch tunnels adopt three layers of liners, as shown in Figure 7. The initial support is composed of $\mathrm{H}-25$ steel piles and $30 \mathrm{~cm}$ thick shotcrete. The secondary liner is composed of I20 steel and $26 \mathrm{~cm}$ thick shotcrete, the final liner consists of $80 \mathrm{~cm}$ thick cast-in-place concrete, and the supporting structure is calculated through elastic model. The initial 


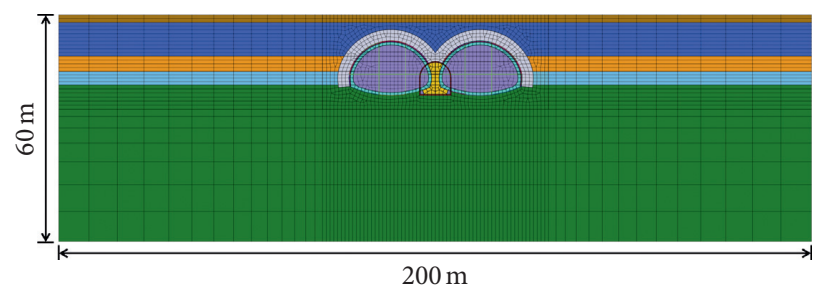

FIGURE 6: FE model of double-arch tunnels.

TABle 1: Soil parameters.

\begin{tabular}{lcccccccc}
\hline Stratum & $H(\mathrm{~m})$ & $\mathrm{P}\left(\mathrm{g} / \mathrm{cm}^{3}\right)$ & $K(\mathrm{~cm} / \mathrm{s})$ & $E(\mathrm{MPa})$ & $K_{0}(-)$ & $C(\mathrm{kPa})$ & $\Phi\left(^{\circ}\right)$ & $\mu(-)$ \\
\hline 1 & 2.0 & 1.95 & $2.31 e-2$ & 24.3 & 0.50 & 10.0 & 27.0 & 0.30 \\
2 B & 9.0 & 2.00 & $5.79 e-3$ & 9.1 & 0.55 & 20.0 & 27.4 & 0.30 \\
2 A & & 2.21 & $1.38 e-5$ & 13.0 & 0.60 & 28.2 & 31.2 \\
5-1 B & 4.0 & 2.64 & $9.26 e-3$ & $3.3 e 3$ & 0.58 & $3.4 e 4$ & 35.0 & 0.24 \\
5-1 A & & 2.69 & $5.56 e-5$ & $4.9 e 3$ & 0.63 & $3.7 e 4$ & 38.6 & 0.27 \\
5-2 B & 3.6 & 2.68 & $2.36 e-4$ & $8.7 e 3$ & 0.64 & $4.1 e 4$ & 39.3 & 0.25 \\
5-2 A & & 2.70 & $3.81 e-5$ & $1.2 e 4$ & 0.68 & $4.5 e 4$ & 42.7 \\
5-3 & 41.4 & 2.71 & $1.16 e-5$ & $4.4 e 4$ & 1.00 & $5.5 e 4$ & 51.8 & 0.23 \\
\hline
\end{tabular}

$h$ : thickness; $\rho$ : density; $K$ : permeability coefficient; $E$ : elastic modulus; $K_{0}$ : at-rest earth pressure coefficient; $c$ : cohesion; $\varphi$ : frictional angle; $\mu$ : Poisson's ratio; B: before grouting; and A: after grouting.

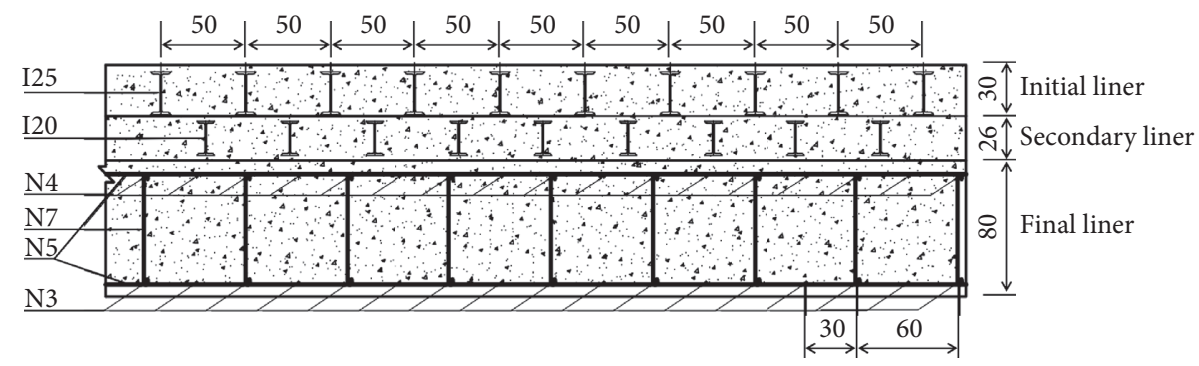

Figure 7: Design of liners of double-arch tunnels.

support and the temporary support were simulated using beam elements. The secondary, final liners, and the middle wall were simulated using solid elements to avoid the direct contact of beam elements in the model. In the process of parameters selection, according to equivalent calculation of compressive stiffness, modulus of concrete is increased to replace the steel arch, and each supporting structure is equivalent to single material with the same compressive stiffness. Table 2 shows the detailed material parameters of the supporting structure.

\subsection{Distribution of Stress Release Ratio of Surrounding Rock.} The double-arch tunnels adopt three layers of liners. Except that parts of stress which were released through deformation, the remaining stress was undertaken by the surrounding rock, the initial support, and the secondary liner altogether. The final support was set mainly for safety and beauty without too much consideration for bearing capacity. The deformation and structural stress of the surrounding rock under different stress release ratios are investigated by changing load release coefficient when excavating the surrounding rock and applying initial support and the secondary liner, thus optimizing the timing of supporting structure. The load release coefficient in the excavation stage refers to the ratio of released stress through deformation to total released stress. But in the stage of applying liners, it refers to the proportion of bearing load on two supporting structures. The shallowly buried double-arch tunnels pass beneath main streets with the complex ground condition and high requirement for deformation control. The surrounding rock should not be exposed for too much time, and the initial support should be timely installed to restrain deformation of the surrounding rock. Therefore, the stress release ratio in the excavation stage should not be more than $30 \%$. According to the design parameters of the support structure, the strength and stiffness of the initial support are both greater than the secondary liner, and thus, the bearing load on the initial support should be greater. The detailed calculation plans are shown in Table 3.

4.3. Results Analysis of Numerical Simulation. A traverse ground deformation curve under different stress release ratio is shown in Figure 8. According to Figure 8, the curve is approximately in shape of "W," and the ground deformation 
TABLE 2: Material parameters of the supporting structure.

\begin{tabular}{|c|c|c|c|c|c|}
\hline Supporting structure & Unit type & $Z(\mathrm{~cm})$ & $\gamma\left(\mathrm{kN} / \mathrm{m}^{3}\right)$ & $E(\mathrm{GPa})$ & $\mu(-)$ \\
\hline Initial support & Beam & 30 & 25 & 34.1 & 0.2 \\
\hline Temporary support & Beam & 30 & 25 & 34.3 & 0.2 \\
\hline Secondary liner & Solid & 26 & 25 & 33.2 & 0.2 \\
\hline Final liner & Solid & 80 & 26 & 35.0 & 0.2 \\
\hline Liner of heading $0 \#$ & Solid & 22 & 25 & 34.0 & 0.2 \\
\hline Middle wall & Solid & - & 26 & 35.0 & 0.2 \\
\hline
\end{tabular}

z: thickness; $\gamma$ : bulk density; $E$ : elastic modulus; and $\mu$ : Poisson's ratio.

Table 3: Distribution of stress release ratio in different stages.

\begin{tabular}{lcccc}
\hline \multirow{2}{*}{ Plan } & \multicolumn{2}{c}{ Stress release ratio in different stages } & Accumulative release ratio (\%) \\
& Tunnel excavation & Initial support & Secondary liner & 100 \\
Plan 1 & 20 & 50 & 30 & 100 \\
Plan 2 & 20 & 60 & 20 & 100 \\
Plan 3 & 30 & 40 & 30 & 100 \\
Plan 4 & 30 & 50 & 20 & \\
\hline
\end{tabular}

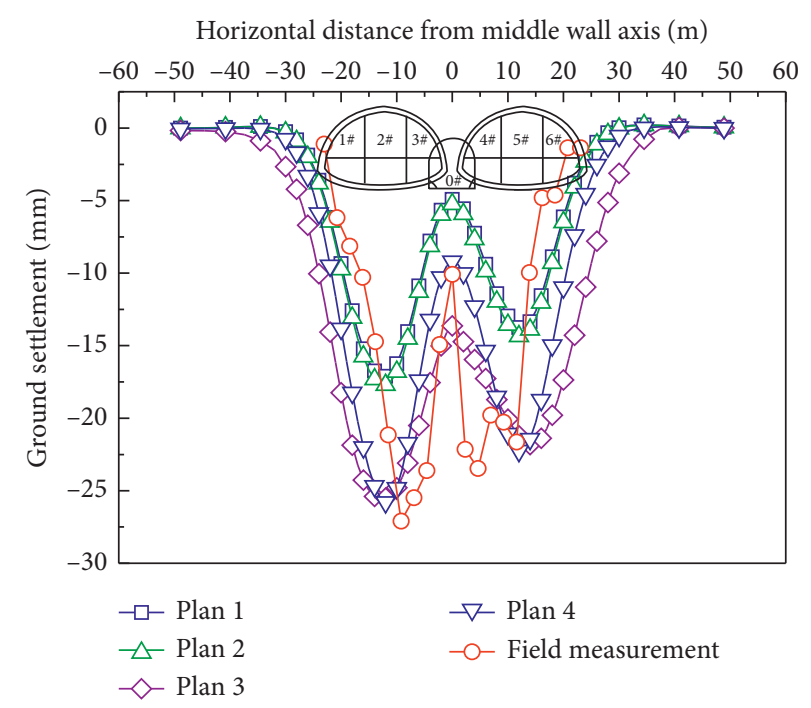

Figure 8: Traverse ground deformation of double-arch tunnels.

is larger above the left and right tunnels and smaller above the middle heading. The maximum ground deformation of the left and right tunnels is, respectively, located on the left side of heading $2 \#$ and the right side of heading $5 \#$. The deformation reduces when away from these two points. Since the left tunnel is excavated first, the ground deformation above accumulates with the progress of excavation, leading to ground deformation of the left tunnel which is larger than that of the right tunnel. The simulated curve of the traverse ground deformation is similar to that of situinspection. Since stress release ratio is different in each excavation stage, the simulation results and monitoring data are different in each plan. Table 4 shows the deformation of the surrounding rock with different distribution of stress release ratio. It can be seen from the table that since the left tunnel of the double-arch tunnels is excavated first, the crown settlement and surface settlement are greater than that of the right tunnel due to the accumulation of ground deformation. Because of the low stress release ratio in the excavation stage, the crown settlement and surface settlement in plan 1 and 2 are obviously less than that in plan 3 and 4 , indicating that timely initial support can effectively control the deformation of the surrounding rock. Compared with plan 1 and plan 3, the secondary liner in plan 2 and 4 was installed later, with more stress release of the surrounding rock and larger collaborative deformation with the initial support. Therefore, the final deformation of the surrounding rock is slightly larger. In the four plans, the horizontal convergence of the left and right tunnels is not obvious, and the structure shows a trend of expansion.

From the numerical simulation results, the axial force or bending moment of the initial support at the six points shown in Figure 9 are relatively larger. These points are selected as the controlling points to check the strength of the 
TABLE 4: Deformation of the surrounding rock under different stress release rates.

\begin{tabular}{|c|c|c|c|c|c|c|}
\hline \multirow[t]{2}{*}{ Plan } & \multicolumn{2}{|c|}{ Crown settlement (mm) } & \multicolumn{2}{|c|}{$\begin{array}{l}\text { Horizontal convergence } \\
(\mathrm{mm})\end{array}$} & \multicolumn{2}{|c|}{$\begin{array}{l}\text { Max. ground settlement } \\
(\mathrm{mm})\end{array}$} \\
\hline & Left & Right & Left & Right & Left & Right \\
\hline Plan 1 & 20.7 & 19.6 & -0.6 & -0.3 & 17.1 & 13.7 \\
\hline Plan 2 & 20.9 & 19.8 & 0 & -0.2 & 17.7 & 14.4 \\
\hline Plan 3 & 27.7 & 25.1 & 0.6 & 0.3 & 25.3 & 21.8 \\
\hline Plan 4 & 28.4 & 25.8 & -0.2 & 0.4 & 25.8 & 22.3 \\
\hline
\end{tabular}

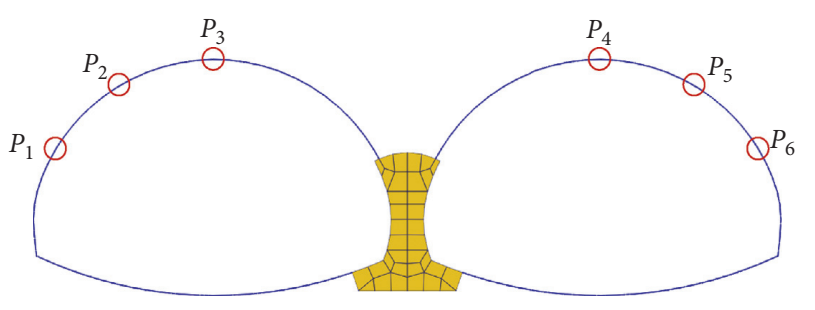

FIgURE 9: Controlling points of initial support.

initial support according to the composite structure design code (JGJ 138-2016) [12]. The safety coefficient of controlling points of the initial support with different stress release ratio distribution of the surrounding rock is shown in Table 5. The axial power at P1 and P6 is larger, with the maximum axial power reaching, respectively, $-792.0 \mathrm{kN}$, $-840.5 \mathrm{kN},-698.8 \mathrm{Kn}$, and $-749.0 \mathrm{kN}$. The bending moment is larger at $P 2$ and $P 5$, with the maximum bending moment reaching $-160.8 \mathrm{kNm},-176.8 \mathrm{kNm},-132.1 \mathrm{kNm}$, and $-148.5 \mathrm{kN} \mathrm{m}$. Due to earlier installation of initial support in plan 1 and 2, the structure bears more loads from the surrounding rock, and the safety coefficient of each controlling point is lower than that of plan 3 and 4 . The safety coefficient of all control points in plan 1, 3, and 4 is not less than 1 while the safety coefficient of P5 in plan 2 is less than 1 , not meeting the requirements of safety control. The maximum principal stress of the secondary liner is shown in Figure 10. In each plan, the stress is larger at the shoulder of the tunnel, with the maximum principal compressive stress reaching $777.9 \mathrm{kPa}, 850.1 \mathrm{kPa}, 743.1 \mathrm{kPa}$, and $805.1 \mathrm{kPa}$, and the maximum principal tensile stress reaching $1251.4 \mathrm{kPa}$, $1029.5 \mathrm{kPa}, 1178.9 \mathrm{kPa}$, and $939.0 \mathrm{kPa}$, meeting the design requirements of the axial compressive strength and flexural strength for the secondary liner.

Above all, although the deformation of the surrounding rock is small in plan 1 and 2 , but the safety coefficient at $P 5$ in plan 2 is less than 1, not meeting the requirements of safety control. The safety coefficient at $P 5$ in plan 1 rightly equals to 1 . Considering the uncertain load and unexpected dynamic load during actual construction, the above two plans are not feasible in terms of safety reservation. Both the surrounding rock deformation and structural stress in plan 3 and 4 meet the design requirements, with plan 3 slightly better than plan 4 . So, the distribution of the stress release ratio at each construction stage in plan 3 is the most reasonable.

\section{Analysis of Installation Time for Secondary Liner}

According to previous studies, it can be approximately assumed that the stress release ratio has a linear relationship with the deformation of the surrounding rock [13]. In this section, the total deformation of the surrounding rock is calculated by fitting processing and regressive analysis of the monitoring data of initial support crown settlement, and then, the proper installation time for the secondary liner is determined considering the reasonable distribution of the stress release ratio.

5.1. Regressive Analysis of Monitoring Data of Crown Settlement. The shallowly buried large-span double-arch tunnels pass beneath main streets, surrounded by densely distributed pipelines and buildings, thus requiring strict deformation control. In order to learn the structure of the tunnel and state of the surrounding rock, it is important to closely monitor the crown settlement of the left and right tunnels. The monitoring section is set up for every $10 \mathrm{~m}$ along the tunnel, and monitoring points are set up in headings $0 \#$ to $6 \#$ for each monitoring section. The whole monitoring project includes 112 monitoring points in total. The layout of the monitoring points is shown in Figure 11. According to the monitoring data at the early stage and the results of numerical simulation, the deformation of heading 1 \# always maintain maximum in the whole process of tunnel construction. To reduce the effects of tunnel construction on surrounding rock deformation in and out of the hole, monitoring data of three sections in the middle of the tunnel are analysed after the installation of the initial support of heading $1 \#$ and before the installation of the secondary liner.

Figure 12 shows the monitoring data of crown settlement in each section of heading $1 \#$. In order to more accurately 
TABLE 5: Safety factor of controlling points of initial support of different plans.

\begin{tabular}{|c|c|c|c|c|c|c|c|}
\hline \multirow{2}{*}{ Plan } & \multirow{2}{*}{ Internal force } & \multicolumn{6}{|c|}{ Controlling points } \\
\hline & & $P 1$ & $P 2$ & $P 3$ & $P 4$ & P5 & P6 \\
\hline \multirow{3}{*}{ Plan 1} & $N$ & -746.6 & -652.0 & -599.3 & -475.1 & -662.0 & -792.0 \\
\hline & $M$ & -8.0 & -128.7 & -45.4 & -107.6 & -160.8 & 37.0 \\
\hline & K & 3.2 & 1.3 & 2.7 & 1.5 & 1.0 & 2.4 \\
\hline \multirow{3}{*}{ Plan 2} & $N$ & -802.1 & -588.3 & -573.4 & -420.4 & -595.1 & -840.5 \\
\hline & $M$ & -10.4 & -137.1 & -52.5 & -122.7 & -176.8 & 40.1 \\
\hline & $K$ & 2.9 & 1.2 & 2.5 & 1.3 & 0.9 & 2.3 \\
\hline \multirow{3}{*}{ Plan 3} & $N$ & -644.4 & -604.7 & -542.1 & -431.1 & -580.1 & -698.8 \\
\hline & $M$ & -6.2 & -110.2 & -37.0 & -87.8 & -132.1 & 30.5 \\
\hline & K & 3.7 & 1.5 & 3.1 & 1.9 & 1.2 & 2.8 \\
\hline \multirow{3}{*}{ Plan 4} & $N$ & -700.7 & -541.2 & -514.0 & -374.9 & -512.7 & -749.0 \\
\hline & $M$ & -8.3 & -118.6 & -44.3 & -103.0 & -148.5 & 33.8 \\
\hline & $K$ & 3.3 & 1.4 & 2.9 & 1.6 & 1.1 & 2.6 \\
\hline
\end{tabular}

$N$ : axial force, $\mathrm{kN} ; M$ : bending moment, $\mathrm{kN} \cdot \mathrm{m}$; and $K$ : safety factor.
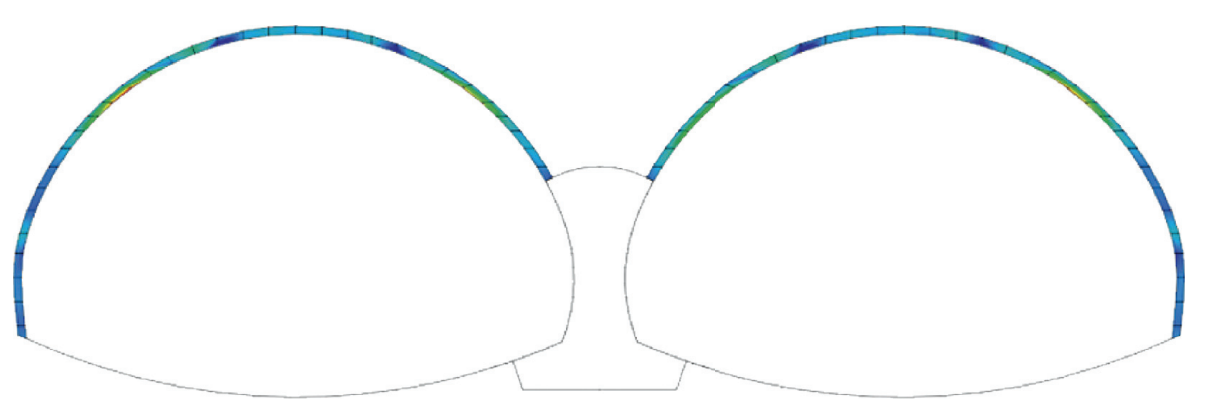

(a)

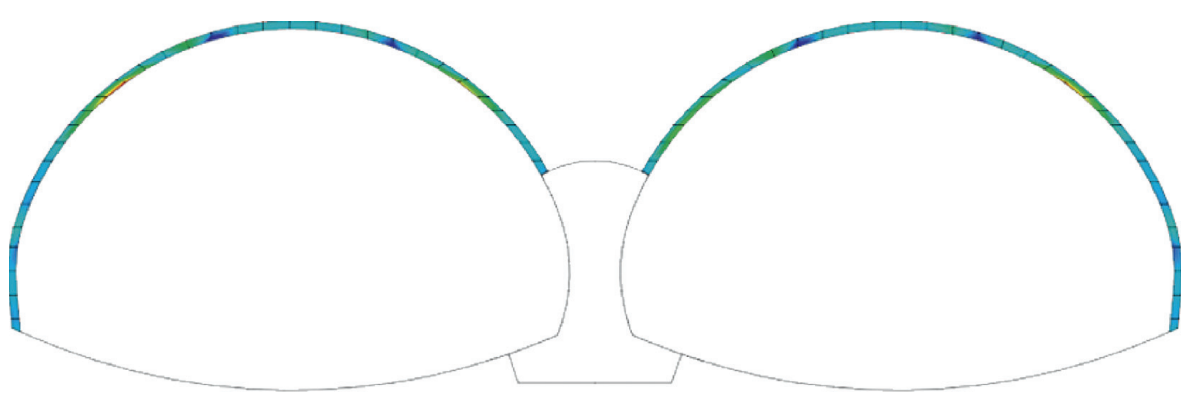

(b)

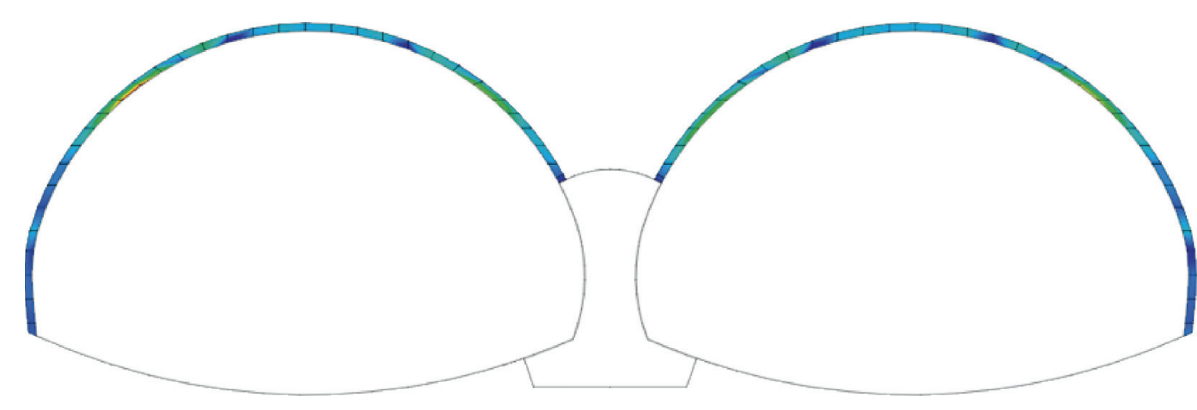

(c)
Plane strain stress S-MAJOR PRIN, $\mathrm{kN} / \mathrm{m}^{-2}$

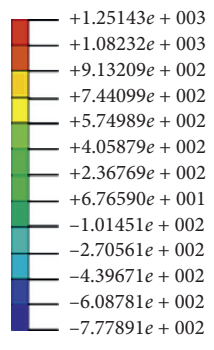

Plane strain stress S-MAJOR PRIN, $\mathrm{kN} / \mathrm{m}^{-2}$

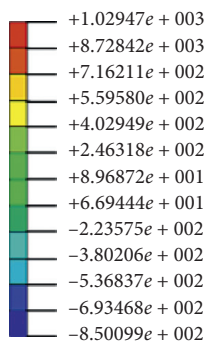

Plane strain stress S-MAJOR PRIN, $\mathrm{kN} / \mathrm{m}^{-2}$

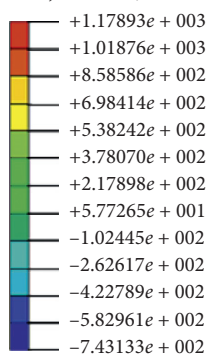

Figure 10: Continued. 


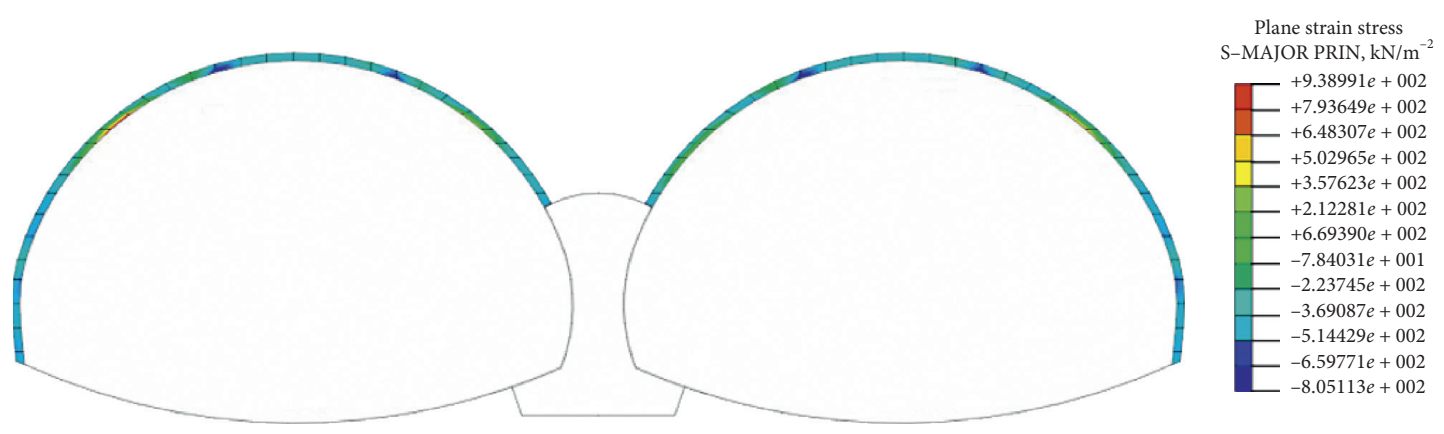

(d)

Figure 10: Maximum principal stress of the secondary liner in the double-arch tunnel. (a) Plan 1. (b) Plan 2. (c) Plan 3. (d) Plan 4.

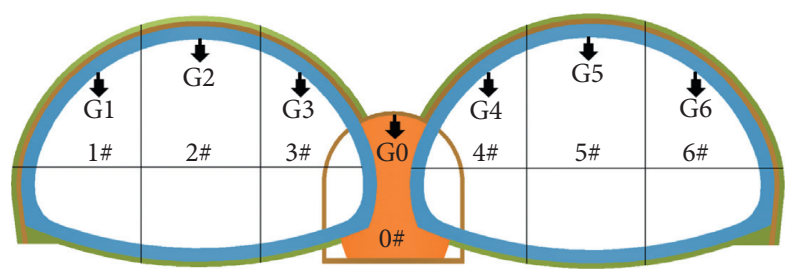

FiguRe 11: Layout of monitoring points in double-arch tunnels.

analyse the deformation law of the initial support and minimize the influence of other factors, exponential function and hyperbolic function are usually adopted to conduct regression analysis of monitoring data $[14,15]$. It can be seen from Figure 12 that the crown settlement of the initial support in each monitoring section changes exponentially over time. The monitoring data of each section is fitted through exponential function in the origin and the exponential function is expressed as below [16]:

$$
U=a\left(e^{-b t}-1\right)
$$

where $a$ and $b$ are regression coefficients. The fitting curve and fitting equation of each section is shown in Figure 12.

Figure 13 is the deformation curve of the surrounding rock during excavation. In fact, the deformation of the surrounding rock starts before excavation but not after excavation. To simplify the expression, this part of deformation is called predisplacement. The deformation of the surrounding rock measured after setting all measured points is called measured displacement. However, the deformation of the surrounding rock also happens before and during the installation, usually known as lost displacement. Both measured displacement and lost displacement are displacement during excavation. Therefore, the actual total displacement of the surrounding rock of this section during tunnel construction is [15] as follows:

$$
\begin{aligned}
& U_{t}=U_{p}+U_{e}, \\
& U_{p}=\frac{\lambda}{1-\lambda} U_{e},
\end{aligned}
$$

$$
U_{e}=U_{l}+U_{m}
$$

where $U_{t}$ is the actual total displacement; $U_{p}$ is the predisplacement, and $\lambda$ is the empirical coefficient representing the proportion of predisplacement in the actual total displacement, usually between 0.265 and 0.33 [16], and the $\lambda$ value is taken as 0.3 according to the geological exploration; $U_{e}$ is the displacement during excavation; $U_{l}$ is the lost displacement; and $U_{m}$ is the measured displacement. According to equation (3), when $t$ tends to infinity, $U_{m}=|-a|=a$; when $t=-t_{1}, U_{l}=a\left(e^{b t_{1}}-1\right) ; t_{1}$ is lag time when reading monitoring data, and the value is taken as 1.0 considering the construction process. According to equation (6),

$$
U_{e}=a+a\left(e^{b t_{1}}-1\right)=a e^{b t_{1}}
$$

Combining equations (4) and (5), equation (8) can be acquired as follows:

$$
U_{t}=\frac{a}{1-\lambda} e^{b t_{1}}
$$

According to equation (8), actual total displacement of the surrounding rock in three monitoring sections is shown in Table 6.

5.2. Determination of Proper Installation Time for Secondary Liner. Due to different ground conditions, design parameters, and construction requirements, supporting time for the secondary liner is different [6-8]. According to the Technical code for engineering of ground anchorages and shotcrete support (GB 50086-2015), when the deformation of 


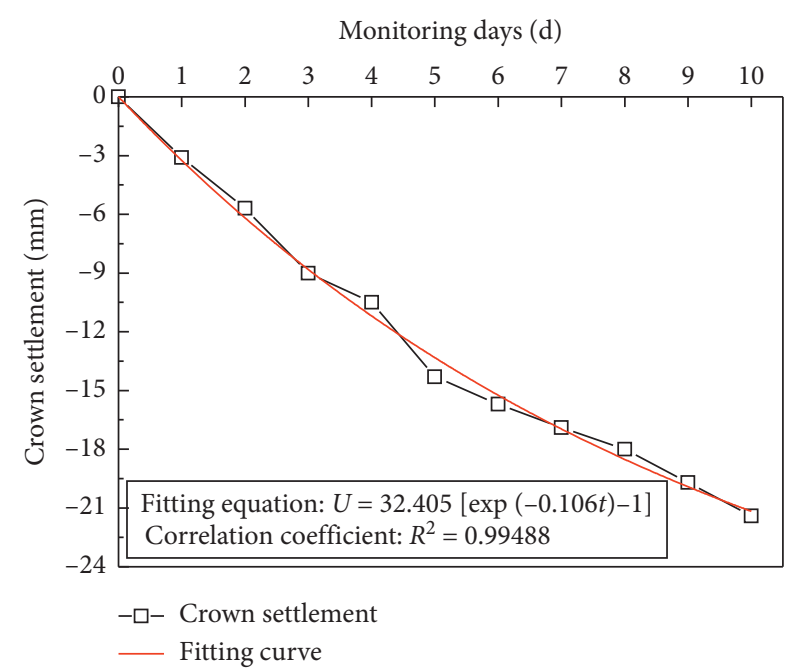

(a)

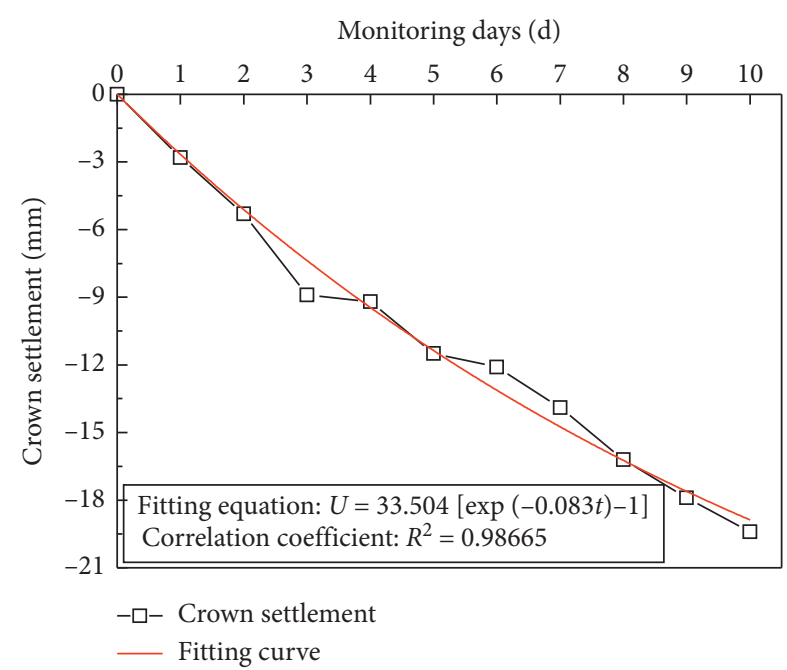

(b)

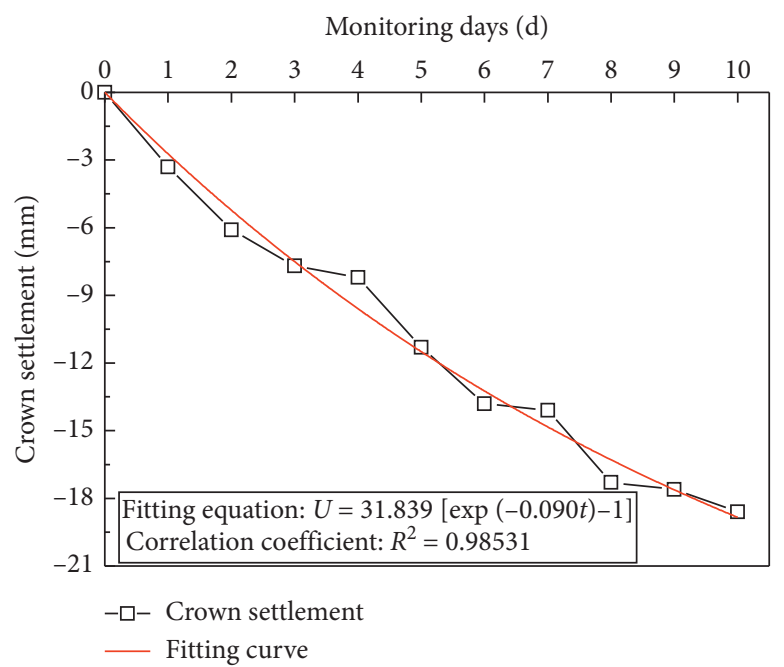

(c)

Figure 12: Monitoring data of crown settlement of initial support in three sections and fitting curve. (a) Section 1. (b) Section 2. (c) Section 3.

the surrounding rock reaches $80 \%-90 \%$ of the total deformation, it can be considered as the reasonable installation time for the secondary liner [17]. The shallowly buried large-span double-arch tunnels in this paper adopt three layers of liners to guarantee the stability and safety of the tunnel. The secondary liner adopts the steel-shotcrete composite structure, and the load undertaken by the secondary liner of double-arch tunnels is different from that in the conventional tunnel. Therefore, the installation time for the secondary liner should be determined based on projects. According to previous analysis, the optimal distribution of the rock release rate is $30 \%$ for the excavation stage, $30 \%$ for the initial support, and $40 \%$ for the secondary liner. In this way, $70 \%$ of stress can be released through deformation or be transferred to liners before the installation of the secondary liner, and the deformation of the surrounding rock can be approximately assumed as $70 \%$ of the total displacement. To sum up, the proper time for the installation of the secondary liner is when the deformation of surrounding rock reaches $70 \%$ of the actual total displacement. For convenience of on-site instruction, $5 \%$ fluctuation space is allowed so that $65 \%$ to $75 \%$ of total deformation is reasonable. Compared with the lining time for two-layer liners, the secondary liner in this project should be installed earlier. The actual and monitored displacement under proper installation time for the secondary liner in each section are calculated and shown in Table 7. Secondary liners are installed when the deformation of three sections, respectively, reaches $33.5-38.6 \mathrm{~mm}, 33.8-39.0 \mathrm{~mm}$, and $32.3-37.3 \mathrm{~mm}$. Monitoring displacement this time is, respectively, $14.4-19.5 \mathrm{~mm}, 15.3-20.5 \mathrm{~mm}$, and $14.4-19.4 \mathrm{~mm}$. 


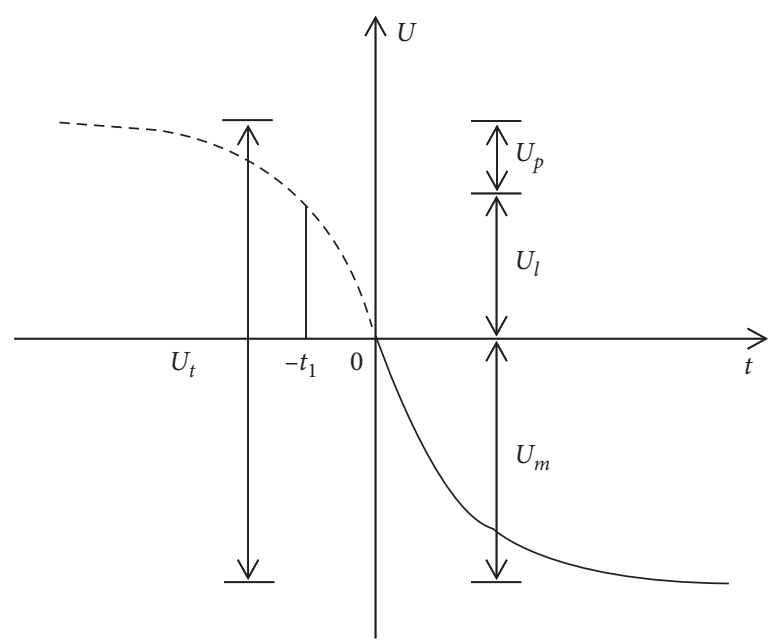

Figure 13: Actual displacement curve of the surrounding rock.

TABLE 6: Fitting equation and actual displacement of each section.

\begin{tabular}{lccc}
\hline Monitoring section & Fitting equation & Relation coefficient & Actual total displacement \\
\hline Section 1 & $U=32.405[\exp (-0.106 t)-1]$ & 0.99488 & 51.5 \\
Section 2 & $U=33.504[\exp (-0.083 t)-1]$ & 0.98665 & 52.0 \\
Section 3 & $U=31.840[\exp (-0.090 t)-1]$ & 0.98531 & 49.8 \\
\hline
\end{tabular}

TABLE 7: Calculated displacement of each section during construction of the secondary liner.

\begin{tabular}{lcccccc}
\hline Monitoring section & $U_{p}(\mathrm{~mm})$ & $U_{l}(\mathrm{~mm})$ & $U_{m}(\mathrm{~mm})$ & $U_{t}(\mathrm{~mm})$ & Actual settlement $(\mathrm{mm})$ & Monitoring settlement $(\mathrm{mm})$ \\
\hline Section 1 & 15.4 & 3.6 & 32.5 & 51.5 & $33.5-38.6$ & $14.4-19.5$ \\
Section 2 & 15.6 & 2.9 & 33.5 & 52.0 & $33.8-39.0$ & $15.3-20.5$ \\
Section 3 & 14.9 & 3.0 & 31.8 & 49.7 & $32.3-37.3$ & $14.4-19.4$ \\
\hline
\end{tabular}

\section{Conclusions}

Based on double-arch tunnels in Xiamen Second Western Passage, this paper improves the distribution of the stress release ratio according to surrounding rock deformation and structural stress. Considering optimal distribution of the stress release ratio, proper installation time for the secondary liner is determined through regressive analysis and fitting processing of monitoring data of initial support crown settlement. The results show that

(1) From the respect of deformation of the surrounding rock, the curve is approximately in shape of "W," and the ground deformation is larger above the left and right tunnels and smaller above the middle heading. The maximum ground deformation of the left and right tunnels is, respectively, located on the left side of heading $2 \#$ and the right side of heading 5\#. The ground deformation of the left tunnel is larger than that of the right tunnel, and the horizontal convergence of the tunnel is not obvious. From the respect of structural stress, the axial power is larger at the waist, and the bending moment is larger at the shoulder of the initial support, and stress is larger at the crown of the secondary liner.
(2) The reasonable distribution of rock release rate is $30 \%$ for the excavation stage, $30 \%$ for initial support and $40 \%$ for the secondary liner. The final support was set mainly for safety and beauty without too much consideration for bearing capacity.

(3) The total displacement of the surrounding rock of three sections after initial support is $51.5 \mathrm{~mm}$, $52.0 \mathrm{~mm}$, and $49.8 \mathrm{~mm}$, respectively. When the deformation of the surrounding rock reach $65 \%-75 \%$ of total displacement, the secondary liner should be installed, and crown settlement is $14.4-19.5 \mathrm{~mm}$, $15.3-20.5 \mathrm{~mm}$, and $14.4-19.4 \mathrm{~mm}$, respectively, at the three monitored sections.

\section{Data Availability}

The data used to support the findings of this study are included within the article.

\section{Conflicts of Interest}

The author declares no conflicts of interest. 


\section{References}

[1] S. Rudolf and L. Christoph, "Swelling rock behaviour in a tunnel: NATM-support vs. Q-support-a comparison," Tunnelling and Underground Space Technology, vol. 24, no. 3, pp. 356-362, 2009.

[2] J. Sulfm, M. Panet, A. Guenot et al., "Closure analysis in deep tunnels," International Journal of Rock Mechanics and Mining Sciences, vol. 24, no. 3, pp. 145-154, 1987.

[3] M. Panet, Recommendation on the Convergence-Confinement Method, Association Francais edes Tunnels et de l'Espace Souterrain (AFTES), Paris, France, 2001.

[4] J. Sulfm, M. Panet, A. Guenot et al., "An analytical solution for time dependent displacement in a circular tunnel," International Journal of Rock Mechanics and Mining Sciences, vol. 24, no. 3, pp. 155-164, 1987.

[5] Y.-W. Pan and J.-J. Dong, “Time-dependent tunnel convergence-I. formulation of the model," International Journal of Rock Mechanics and Mining Sciences and Geomechanics Abstracts, vol. 28, no. 6, pp. 469-475, 1991.

[6] Z. C. Liu, W. J. Li, Y. Q. Zhu et al., "Research on construction time of secondary lining in soft rock of large-deformation tunnel," Chinese Journal of Soil Mechanics and Engineering, vol. 27, no. 3, p. 580, 2008.

[7] O. C. Sung and H. S. Shin, "Stability analysis of a tunnel excavated in a weak rock mass and the optimal supporting system design," International Journal of Rock Mechanics and Mining Sciences, vol. 41, no. 3, pp. 876-881, 2007.

[8] Y. Zhou, J. X. Liu, J. Q. Fang et al., "Numerical simulation for appropriate lining time of tunnel considering rock mass rheological conditions," Soil Mechanics, vol. 33, no. 01, pp. 268-272, 2012.

[9] K. Thomas and M. Gunther, "A numerical study of the effect of soil and grout material properties and cover depth in shield tunnelling," Computers and Geotechnics, vol. 33, pp. 234-247, 2006.

[10] F. B. Kannen and P. Borut, "Displacement analysis of tunnel support in soft rock around a shallow highway tunnel at Golovec," Engineering Geology, vol. 75, no. 1, pp. 89-106, 2004.

[11] G. Galli, A. Grimaldi, A. Leonardi et al., "Three-dimensional modelling of tunnel excavation and lining," Computers and Geotechnics, vol. 31, no. 3, pp. 171-183, 2004.

[12] GJ 138-2016, "Code for composite structure design," International Journal of Rock Mechanics and Mining Sciences, 2016.

[13] Z. H. Chang, Study on Initial Installation Time of Support System Based on FLAC ${ }^{3 D}$, Wuhan University, Wuhan, China, 2017.

[14] T. Unlut and H. Gercek, "Effect of Poisson's ratio on the normalized radial displacements occurring around the face of a circular tunnel," Beijing China building Industry Press, vol. 18, no. 4, pp. 547-553, 2003.

[15] C. Carranza-Torres and C. Fairhurst, "Application of the convergence-confinement method of tunnel design to rock masses that satisfy the Hoek-Brown failure criterion," Tunnelling and Underground Space Technology, vol. 15, no. 2, pp. 187-213, 2000.

[16] J. Y. Wang, Principles of Tunnel Engineering Monitoring and Information Design, China Railway Publishing House, Beijing, China, 1990.

[17] GB 50086-2015, Technical Specifications for Rock Bolt and Shotcrete Support Engineering, China Planning Publishing House, Beijing, China, 2015. 